Design and Application of External Reference Electrode for Kinetic Studies at Elevated Temperatures and Pressures

Fleige, Michael; Wiberg, Gustav Karl Henrik; Arenz, Matthias

Published in:

Journal of The Electrochemical Society

DOI:

10.1149/2.1051707jes

Publication date:

2017

Document version

Publisher's PDF, also known as Version of record

Document license:

CC BY-NC-ND

Citation for published version (APA):

Fleige, M., Wiberg, G. K. H., \& Arenz, M. (2017). Design and Application of External Reference Electrode for Kinetic Studies at Elevated Temperatures and Pressures. Journal of The Electrochemical Society, 164(7), F821F824. https://doi.org/10.1149/2.1051707jes 


\title{
Design and Application of External Reference Electrode for Kinetic Studies at Elevated Temperatures and Pressures
}

\author{
Michael J. Fleige, ${ }^{a}$ Gustav K. H. Wiberg, ${ }^{b, *}$ and Matthias Arenz ${ }^{a, b, z}$ \\ ${ }^{a}$ Nano-Science Center, Department of Chemistry, University of Copenhagen, DK-2100 Copenhagen $\emptyset$, Denmark \\ ${ }^{b}$ Department of Chemistry and Biochemistry, University of Bern, CH-3012 Bern, Switzerland
}

\begin{abstract}
We present the design and application of an external reference electrode (RE) system for kinetic studies of the oxygen reduction reaction (ORR), the cathode process in high temperature proton exchange membrane fuel cells (HT-PEMFCs), at elevated temperatures and pressures inside an autoclave. The RE system comprises a solid ion-conducting junction based on Nafion tubing. External RE was a reversible hydrogen electrode (RHE) calibrated reproducibly relative to an internal RHE with an uncertainty $< \pm 5 \mathrm{mV}$ over the temperature range of $25-170^{\circ} \mathrm{C}$. Functionality of the RE system was tested by measuring ORR in concentrated $\mathrm{H}_{3} \mathrm{PO}_{4}$ relative to a calibrated external RHE. Thus, we are confident that the development is a useful and versatile tool for kinetic studies at elevated temperatures and pressures.

(C) The Author(s) 2017. Published by ECS. This is an open access article distributed under the terms of the Creative Commons Attribution Non-Commercial No Derivatives 4.0 License (CC BY-NC-ND, http://creativecommons.org/licenses/by-nc-nd/4.0/), which permits non-commercial reuse, distribution, and reproduction in any medium, provided the original work is not changed in any way and is properly cited. For permission for commercial reuse, please email: oa@electrochem.org. [DOI: 10.1149/2.1051707jes] All rights reserved.

(cC) BY-NC-ND
\end{abstract}

Manuscript submitted March 20, 2017; revised manuscript received May 2, 2017. Published May 24, 2017.

Fast and reliable testing of fuel cell catalysts at relevant conditions is of high importance for academia and industry alike. Recently, we introduced an elevated pressure and temperature rotating disk electrode (RDE) system that allows electrocatalytic measurements under well-defined mass transport conditions $s^{1,2}$. The setup comprised an internal silver wire RE that enabled a stable determination of the reference potential, but the obtained calibration relative to an internal RHE lacked the required accuracy $(< \pm 5 \mathrm{mV})$ for accurate kinetic measurements. We therefore avoided in our previous work the determination of absolute kinetic rates of the ORR at elevated temperature and pressure. An approach to more reliable reference potentials in pressurized cells is to use external RE configurations. ${ }^{3}$ Recently, external RE systems for fuel cells with solid ion-conducting junctions based on Nafion tubing or the $\mathrm{PBI} / \mathrm{H}_{3} \mathrm{PO}_{4}$ polymer were published. ${ }^{4,5}$ Here we present the design and test of an external RE system with solid junction specifically developed for pressurized electrochemical cells. The most meaningful RE to study ORR with respect to fuel cells is the RHE, which is a hydrogen electrode immersed in the same electrolyte and at 1 bar $\mathrm{H}_{2}$ partial pressure. ${ }^{6}$ Thus, we applied an external RHE and calibrated it separately relative to an internal RHE, as its determination in $\operatorname{situ}^{7,8}$ is not practical in pressurized cells. Application of the calibrated external RE was tested for studying ORR in conc. $\mathrm{H}_{3} \mathrm{PO}_{4}$ at elevated temperatures. Such conditions are highly relevant for high temperature proton exchange membrane fuel cells (HT-PEMFC), but usually not accessible to RDE studies due to the low oxygen solubility in the electrolyte. The results demonstrate that our development enables meaningful kinetic studies in pressurized cells and thereby overcomes the significant accuracy issues related to internal REs operated at elevated temperatures.

\section{Experimental}

The electrolyte used in this study was $85 \mathrm{wt} \% \mathrm{H}_{3} \mathrm{PO}_{4}$ (Suprapur, Merck). The gases used were supplied from gas cylinders (Air Liquide, Denmark) and had a purity of at least $99.995 \%$. The electrochemical cell was placed inside an autoclave as described previously. ${ }^{1,2}$ Counter electrode was Pt mesh. The working electrode was either identical to the RHE or a Pt rotating disk $(\mathrm{d}=2 \mathrm{~mm})$.

Design of external RE system.-The RE is arranged outside of the autoclave by means of a pressurized electrolyte bridge comprising a solid ion-conducting junction. The main components are a T-section

*Electrochemical Society Member.

${ }^{\text {z} E-m a i l: ~ m a t t h i a s . a r e n z @ d c b . u n i b e . c h ~}$ with incorporated junction, a RE container, and a needle valve to control the electrolyte filling in the tube leading to the RE compartment. A system schematic is depicted in Fig. 1, which shows the junction more detailed.

The ion-conducting material was Nafion tubing TT-110 (Perma Pure, USA) with a rated internal pressure of 5 bar. A $20 \mathrm{~mm}$ long piece of tubing was cleaned and activated for ion-conduction by a treatment involving $5 \mathrm{wt} \% \mathrm{H}_{2} \mathrm{O}_{2}$ and $8 \mathrm{wt} \% \mathrm{H}_{2} \mathrm{SO}_{4} .{ }^{9}$ We found that squeezing the Nafion tubing between a cylinder and surrounding tubing is adequate for creating a solid ion-conducting junction that is stable and non-leaking up to a maximum tested pressure of 25 bar. To build a solid cylinder, a silver wire of $0.5 \mathrm{~mm}$ diameter and 15 $\mathrm{mm}$ length was inserted in polytetrafluorethylene (PTFE) tubing with

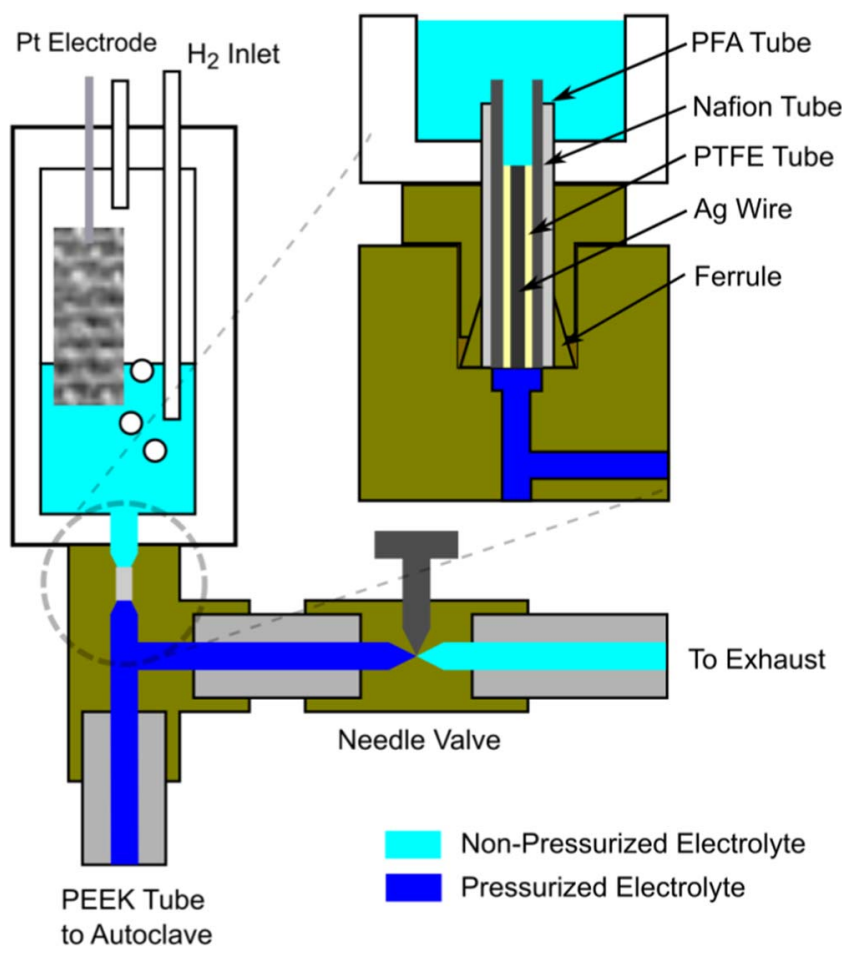

Figure 1. Schematic drawing of the external RE system consisting of a RE container for RHE, a T-section, and a needle valve. The detail shows an assembly of the pressurized ion-conducting junction based on Nafion tubing. 
the same length and inner diameter (i.d.), and outer diameter (o.d.) of $1.6 \mathrm{~mm}$. Perfluoralkoxy alkane (PFA) tubing having i.d. of $2.0 \mathrm{~mm}$ and o.d. of $3.2 \mathrm{~mm}$ enclosed the Nafion tubing. The entire assembly 'PFA/Nafion/PTFE-silver' was mounted flush in a T-section for 1/8, tubing (P-713, Idex, USA) made of polyetheretherketone (PEEK) and then compressed by the ferrule sealed connection. The flush lying end of Nafion tubing covered the through-hole of the T-section, which was slightly enlarged to improve access of $\mathrm{H}_{3} \mathrm{PO}_{4}$ to the Nafion tubing. Around its exposed end, a RE container was built. It consisted of PFA tubing with i.d. of $6 \mathrm{~mm}$ and its lid was a tight-fitting PTFE nut modified with bores for hydrogen inlet and electrode lead.

The electrolyte bridge to the electrochemical cell was PEEK tubing with o.d. of $3.2 \mathrm{~mm}$ and i.d. of $1.6 \mathrm{~mm}$ (Latek, Germany). It was fed through the autoclave lid using a Swagelok fitting (SS-200-1-ORBT), and it extended until short of the bottom of the electrochemical cell. The length between fitting and T-section was $6 \mathrm{~cm}$. The needle valve (P-447, IDEX, USA) was connected to the middle branch of the T-section.

Fabrication of RE.-The external RE consisted of nano-dispersed Pt/C catalyst (TEC10E50E-HT, TKK, Japan) deposited on gas diffusion layer (GDL) Sigracet 10 BC (SGL Carbon, Germany) with a geometrical area of approx. $0.8 \mathrm{~cm}^{2}$. The catalyst loading was $1 \mathrm{mg}_{\mathrm{Pt} / \mathrm{C}} \mathrm{cm}^{-2}$. The lead attached to the GDL was a Pt-wire. An amount of approx. $1 \mathrm{ml} \mathrm{H}_{3} \mathrm{PO}_{4}$ was filled into the RE container. Before immersing the $\mathrm{Pt} / \mathrm{C}$ covered GDL, the entire catalyst layer was soaked in $\mathrm{H}_{3} \mathrm{PO}_{4}$. In the $\mathrm{RE}$ container, only about $20 \%$ of the $\mathrm{Pt} / \mathrm{C}$ covered area was immersed in acid to expose the acid-soaked Pt/C layer efficiently to hydrogen gas. Hydrogen was not humidified, since water vapor pressure of $85 \mathrm{wt} \% \mathrm{H}_{3} \mathrm{PO}_{4}$ is negligible at RT. An identical $\mathrm{Pt} / \mathrm{C}$ electrode, as described above, was prepared for calibration purposes and was used in the pressure cell.

RHE calibration measurement.-The temperature dependent potential difference $(E)$ between an electrode kept inside the pressure cell and the external RHE was measured in the range of RT to $170^{\circ} \mathrm{C}$. $E$ was measured both during heating and cooling of the pressurized cell. The internal $\mathrm{H}_{2}$-elecrode was kept in a jar made of PFA (Savillex) and immersed in $85 \mathrm{wt} \% \mathrm{H}_{3} \mathrm{PO}_{4}$ equivalent to the external electrode. Before the measurement, the electrolyte of the internal cell was vigorously purged with hydrogen, and the carefully hydrogen-saturated cell was additionally pressurized to 3 bar (abs) using Argon, to prevent the water fraction in the acid from boiling, and to enable releasing small quantities of electrolyte at the needle valve.

ORR testing.- The ORR was measured at $100^{\circ} \mathrm{C}$; an improved version of the RDE setup and fabrication of a polycrystalline Pt RDE tip embedded in a polymer melt are described in more detail below. Before heating the cell, the electrolyte was purged for at least 2 hours followed by pressurizing to 3 bar (abs) using Argon. Then, the cell was heated to $100^{\circ} \mathrm{C}$. Before the ORR test commenced, cyclic voltammograms (CV) in Argon-saturated electrolyte were recorded to check the characteristics of the electrode and to enable correction of ORR polarization curves for non-faradaic background currents. ${ }^{10,11}$ The CVs were collected at 3.8 bar (abs) cell pressure, since the pressure of Argon increases with temperature. In the next step, additional 10 bar of oxygen were filled into the cell yielding a total cell pressure of 13.8 bar (abs). The RDE was rotated at $1,600 \mathrm{rpm}$ to aid dissolution of oxygen in the acid until ORR currents stabilized. The CVs recorded at 3.8 bar cell pressure were used for background correction of the ORR polarization curves measured at $13.8 \mathrm{bar}$, since in separate tests with Argon-saturated cells, no changes in the shape of the CV were observed when the pressure of Argon was increased. This is also in line with earlier studies dealing with Pt electrochemistry at very high pressures. The pressure difference of 10 bar can be neglected, as the electrochemical features of smooth Pt electrodes are practically identical in the low-pressure regime.

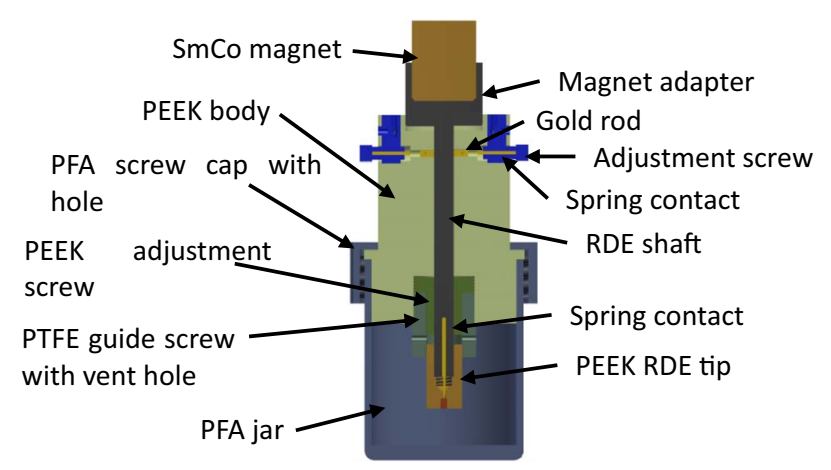

Figure 2. Cross-sectional view of the improved design of the RDE setup.

Further design improvements of the RDE setup.-Further design improvements compared to our previous setup ${ }^{2}$ are the chemical resistance of the cell container, the bearing of the RDE shaft, sliding contact and magnet coupling. Chemical resistance to conc. $\mathrm{H}_{3} \mathrm{PO}_{4}$ at elevated temperatures is improved using a jar made of PFA $(90 \mathrm{ml}$ standard jar, Savillex, USA) as cell container in preference to the previous borosilicate glass flask. ${ }^{12}$ Furthermore, the lower height of the jar allows using a stronger magnet (SmCo magnet E755, Eclipse, UK) than previously. In the PFA screw cap belonging to the jar, a hole was made to use the cap for attaching the PEEK body placed above the jar. The body guides the RDE shaft and contains the sliding contact. Low heat expansion and softening of the PEEK body improves the lateral bearing of the RDE shaft at elevated temperatures compared to the previous design. The RDE shaft is supported such that it is fixed with minimal backlash between PTFE guide screw and PEEK body, which ensures that the large backlash necessary to compensate for expansion of the PEEK body cannot lead to notable vertical oscillation of the RDE shaft. The shaft with screw-in adapter to attach the magnet is lathed from one piece of stainless steel for optimal concentricity. It has thread for attaching the PEEK backlash adjustment screw and contains a vent hole in the area of the RDE tip to enable pressure compensation at the back side of the latter. Thread is made on the lateral surface of the SmCo magnet so that it can be screwed in the adapter. The sliding contact is designed as double contact made of gold rod 2.0 $\mathrm{mm}$ in diameter placed in $2.2 \mathrm{~mm}$ channels. The gold rod is pressed on the RDE shaft by a small gold plated spring contact (PTR 1010-D$0.8 \mathrm{~N}-\mathrm{AU}-1.0, \mathrm{PTR}$, Germany) inserted into an adjustment screw with hole. To reduce abrasion of gold and PEEK, which may affect the sliding contact, the RDE shaft is wet-sanded using sandpaper down to minimum grit size P4000. Electrical contact between RDE shaft and RDE tip is made using the same kind of spring contact as in the sliding contact. The cell setup is shown schematically in Fig. 2.

Fabrication of polycrystalline Pt RDE tip.-In experiments at elevated temperatures, pressures, and especially a combination of both, it is difficult to maintain a perfect lateral seal of the electrode disk in a RDE tip. We tested in this study embedding the disk in a melt of insulating plastic to obtain a metal-plastic bond without crevices. First, a degreased polycrystalline Pt rod $(99.99 \%$ purity, Chempur, Germany) $2.0 \mathrm{~mm}$ in diameter and $5 \mathrm{~mm}$ in length is inserted with tight fit in a PEEK plastic insulator tip $11 \mathrm{~mm}$ in diameter. ${ }^{13}$ Then, a tight fitting aluminum ring with $5 \mathrm{~mm}$ thickness is put over the plastic tip comprising the Pt rod. The assembly is placed in a PTFE holder that ensures a stable vertical orientation followed by heating it to $150^{\circ} \mathrm{C}$ using a heat gun. Upon heating, the aluminum ring compresses PEEK cylinder and Pt rod due to the differences in heat expansion coefficient of aluminum and PEEK. Embedding the Pt rod is finalized by melting a fraction of PEEK plastic in contact to Pt. A ground smooth tip of a hot (above the melting point of PEEK, $343^{\circ} \mathrm{C}$ ) soldering iron is carefully pressed on the Pt surface. The hot tip is removed after the plastic has formed a rim of melt around the Pt rod, which indicates that the rod is surrounded by melt. The assembly is left to 


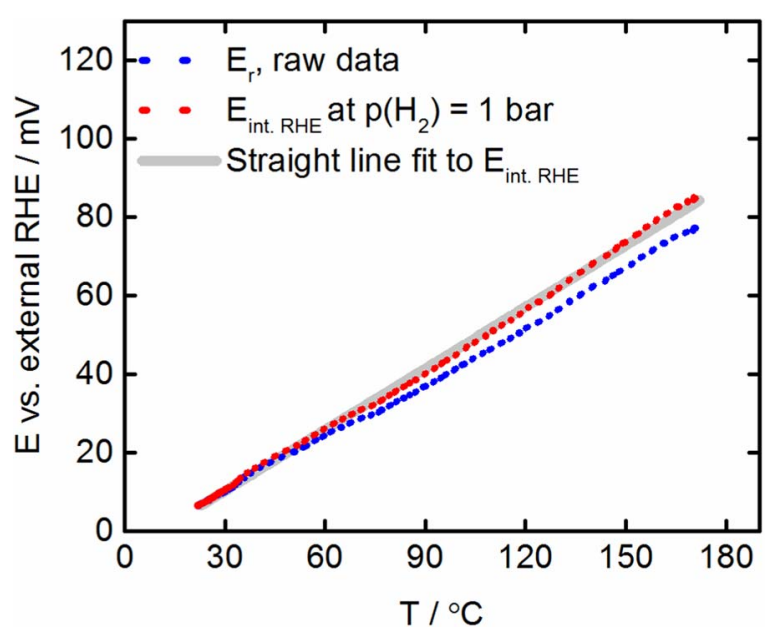

Figure 3. Measured temperature dependent potential $E$ of internal $\mathrm{H}_{2}$ electrode (blue dotted line) relative to external RHE. Potential of RHE of the internal electrode, $E_{\text {int. }} R H E$, is obtained after correcting $E_{r}$ to 1 bar $\mathrm{H}_{2}$ partial pressure (red dotted line). A straight line (gray) was fitted to the data of $E_{\text {int }}$ RHE representing the calibration curve of the system.

cool slowly to form the metal-plastic bond and finally polished and cleaned following standard procedures. ${ }^{13}$

\section{Results and Discussion}

An exemplary measurement of the potential $E$ of internal $\mathrm{H}_{2}-$ electrode over the temperature range RT to $170^{\circ} \mathrm{C}$ relative to external RHE at RT is presented in Fig. 3. Upon heating, the measurement curves are bow-shaped (not shown), whereas during cooling straight curves are observed. This is ascribed to an uneven temperature distribution during heating, i.e. the internal $\mathrm{H}_{2}$-electrode has a higher temperature than the thermocouple. During cooling the temperature gradient is negligible. Thus, we choose to evaluate only the cooling data.

The measured raw data of $E$ are denoted with $E_{r}$ in the Fig. 3. Temperature elevation clearly makes $E$ more positive. Analogously, $\mathrm{H}_{2}$ partial pressure increases also with temperature. Thus, in order to obtain the internal RHE value, $E_{r}$ was corrected to 1 bar $\mathrm{H}_{2}$ partial pressure using the following relation given by Spitzer and Wunderli ${ }^{6}$

$$
\Delta E=\frac{R T}{2 F} \times \ln \left(\frac{p\left(H_{2}\right)}{p^{\ominus}}\right)
$$

with $R$ the gas constant, $T$ the absolute temperature [K], $F$ the Faraday constant, $p\left(\mathrm{H}_{2}\right)$ the $\mathrm{H}_{2}$ partial pressure as function of temperature, and $p^{\ominus}$ the $\mathrm{H}_{2}$ partial pressure at RT, approx. 1 bar. As we assume that the temperature dependent $\mathrm{H}_{2}$ partial pressure can be described as isochoric process of an ideal gas, the $\mathrm{H}_{2}$ pressure terms in Eq. 1 can be replaced by temperatures, and the potential of internal RHE $\left(E_{\text {int. } R H E}\right.$ ) can then be calculated as follows:

$$
E_{\text {int. } R H E}=E_{r}+\frac{R T}{2 F} \times \ln \left(\frac{T}{T^{\mathrm{o}}}\right)
$$

As shown in Fig. 3, the data points form a more or less straight line. Thus, a linear fit can be applied to the curve of $E_{i n t . R H E}$. This fitted straight line represents the calibration curve of the system from which we obtain the temperature coefficient. The mean $\mathrm{H}_{2}$-pressure corrected temperature coefficient obtained from three calibration measurements was $0.49 \pm 0.03 \mathrm{mV}^{\circ} \mathrm{C}^{-1}$. Thus, the maximum uncertainty at the highest temperature, $170^{\circ} \mathrm{C}$, was $\pm 4.5 \mathrm{mV}$. Hence, the external RE system is sufficiently accurate to study the kinetics of electrocatalytic reactions such as ORR at elevated temperatures and pressures. It is worth mentioning that a theoretical temperature coefficient of the hydrogen electrode of $0.5 \mathrm{mV}^{\circ} \mathrm{C}^{-1}$ was reported earlier for 0.1 $\mathrm{mol} / \mathrm{L} \mathrm{H}_{2} \mathrm{SO}_{4} \cdot{ }^{14}$ Following the theoretical relation for the temperature

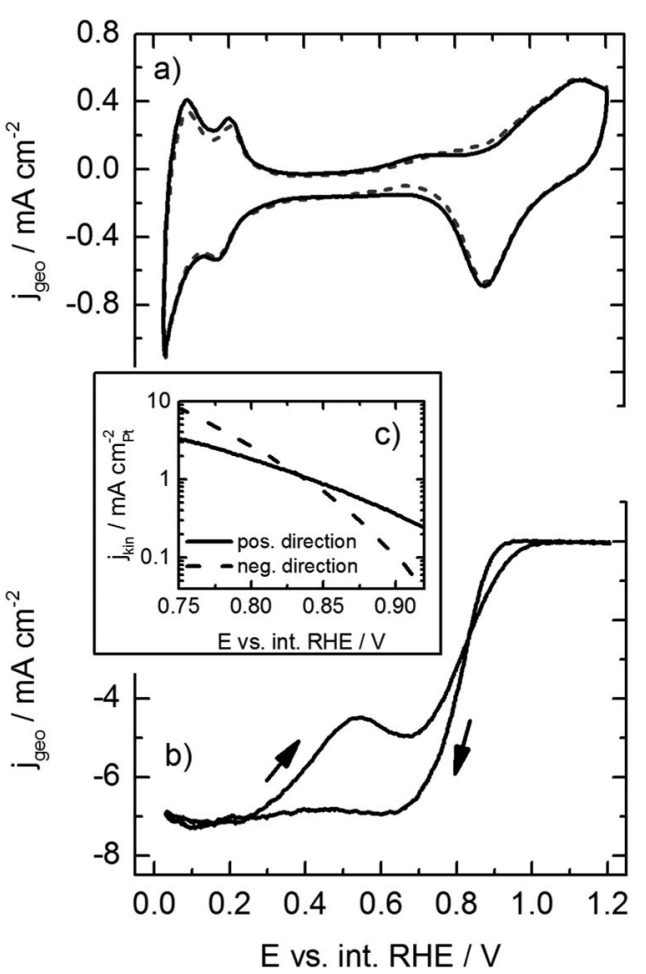

Figure 4. ORR experiment at $100^{\circ} \mathrm{C}$ using the calibrated external RHE; a) CVs recorded in Argon-saturated electrolyte; solid line: without RDE rotation, dashed line: with RDE rotation; b) CVs recorded in Oxygen-saturated electrolyte at $\mathrm{p}_{\mathrm{O}_{2}}=10 \mathrm{bar}$; The $\mathrm{CV}$ recorded in Argon saturated solution was subtracted; c) Tafel plot of the Pt surface area specific ORR activity in b); sweep rate $=100 \mathrm{mV} \mathrm{s}^{-1}$, rotation rate $=1,600 \mathrm{rpm}$.

coefficient

$$
\frac{\partial E}{\partial T}=\frac{\Delta S^{\circ}}{2 F}-\frac{R}{2 F} \ln \frac{p\left(H_{2}\right)}{\left[a_{H^{+}}\right]^{2}}
$$

with $\Delta S^{\circ}$ as the standard entropy change of the of the reaction, 130.6 $\mathrm{J} \mathrm{mol}^{-1} \mathrm{~K}^{-1}$ for $\mathrm{H}_{2}(\mathrm{~g}), a_{H^{+}}$the proton activity of the acid, and $p\left(H_{2}\right)$ the hydrogen partial pressure, to obtain the measured temperature coefficient a proton activity of $a_{H^{+}}=0.3 \mathrm{~mol} / \mathrm{L}$ has to be assumed for the $85 \mathrm{wt} \% \mathrm{H}_{3} \mathrm{PO}_{4}$, which is a reasonable value.

It was noticed that at RT conditions $E$ differed by $7 \pm 1 \mathrm{mV}$ in the presented calibration measurement, but the difference slowly decreased with prolonged use of the system and was $0 \mathrm{mV}$ in a later calibration. Since at isothermal conditions internal and external $\mathrm{H}_{2}$ electrode should be equal in potential, the offset is ascribed a junction potential, $E_{\text {junction }}$, at the interface Nafion/ $\mathrm{H}_{3} \mathrm{PO}_{4}$. Due the possible existence of this offset, it is advisable to perform a check including two $\mathrm{H}_{2}$-elctrodes in every measurement series. We formulate a simplified expression to obtain the potential of the internal RHE at elevated temperatures for this system as:

$$
E_{\text {int. } R H E}(T)=0.49 \frac{\mathrm{mV}}{{ }^{\circ} \mathrm{C}}(T)+E_{\text {junction }}
$$

Given the now known internal RHE, we carried out a kinetic test measurement at $100^{\circ} \mathrm{C}$ and 10 bar oxygen partial pressure with calibrated external RHE. The results are presented in Fig. 4. Basic CVs with and without RDE rotation are given in Fig. 4a. Its main features are typical for $\mathrm{Pt}$ in oxygen-free $\mathrm{H}_{3} \mathrm{PO}_{4}$ electrolyte and have been discussed previously. ${ }^{1,13,15,16}$ An oxidation feature is visible at $0.7 \mathrm{~V}$ in the positive going scan. Upon rotation, a small oxidative current appears also in the back scan around $0.7 \mathrm{~V}$. The ORR polarization curve after subtraction of the basic CV is depicted in Fig. 4b. In negative scan direction the ORR commences at about $0.95 \mathrm{~V}$ and at $0.65 \mathrm{~V}$ the geometrical current density, $j_{g e o}$, reaches its limiting value 
$7 \mathrm{~mA} \mathrm{~cm}^{-2}$. For comparison, in dilute electrolytes at RT and $1 \mathrm{bar}$ oxygen partial pressure, $6 \mathrm{~mA} \mathrm{~cm}^{-2}$ is the typical limit at same rotation rate. ${ }^{17}$ Thus, oxygen mass transport is comparable and even slightly larger in this study. Focusing on positive scan direction, $j_{\text {geo }}$ diminishes above $0.25 \mathrm{~V}$, reaches a minimum at $0.54 \mathrm{~V}$, and increases again until a maximum is reached at $0.68 \mathrm{~V}$. We described similar results previously in $0.5 \mathrm{~mol} \mathrm{dm}{ }^{-3} \mathrm{H}_{3} \mathrm{PO}_{4}$ at $80^{\circ} \mathrm{C} .{ }^{13}$ In the range above $0.7 \mathrm{~V}$ the apparent activity has significantly different slopes depending on scan direction. At $0.83 \mathrm{~V}, j_{\text {geo }}$ equals in both scan directions, but above $0.83 \mathrm{~V} j_{\text {geo }}$ is larger in the positive scan. Above $1.05 \mathrm{~V}$ no ORR occurs. The kinetics of the apparent ORR activity is analyzed in a Tafel plot presented in Fig. $4 \mathrm{c}$ that is briefly discussed hereafter. It is desired to refer the kinetic activity to the real surface area of Pt. Typically, the Pt surface area is evaluated by measuring the surface charge of $\mathrm{Pt}$ in a CO-stripping experiment or based on the hydrogen desorption peaks $\left(\mathrm{H}_{\text {upd }}\right)$. Although $\mathrm{CO}$-stripping is considered more reliable for elevated temperature measurements, its use in the pressurized cell is not practical. Therefore, we used as measure of the Pt surface area only the charge of $\mathrm{H}_{\text {upd }}$ obtained from integration of the hydrogen desorption peaks ${ }^{18}$ in Fig. 4a. As normalization factor, we used a specific charge of $195 \mu \mathrm{C} \mathrm{cm}^{-2} \mathrm{Pt}$, a value commonly used for room temperature conditions. It is known that with increasing temperature this $\mathrm{H}_{\text {upd }}$ charge decreases, but in the confined cell setup no systematic evaluation of the temperature dependence, which ideally requires single crystals is feasible. The kinetic current density, $j_{k i n}$, was normalized by the thus defined real $\mathrm{Pt}$ surface area (roughness factor $=3.2$ ). In positive direction, $j_{k i n}$ at $0.9 \mathrm{~V}$ is $0.36 \mathrm{~mA} \mathrm{~cm}^{-2} \mathrm{Pt}$; for comparison, $2.7 \mathrm{~mA} \mathrm{~cm}^{-2} \mathrm{Pt}$ (not background corrected) were reported earlier for polycrystalline $\mathrm{Pt}$ in $\mathrm{HClO}_{4}$ electrolyte at $60^{\circ} \mathrm{C}$ and ambient pressure. ${ }^{19}$ In this study, comparable kinetics was first achieved at 0.8 V. This finding demonstrates the highly inhibiting character of conc. phosphoric acid.

\section{Conclusions}

The presented external RE system enables reliable and convenient application of a RHE to study electrochemical reactions in pressurized cells at elevated temperatures. The data demonstrate that the temperature dependent potential of an internal RHE relative to the external RHE can be calibrated with satisfying reproducibility $(< \pm 5 \mathrm{mV})$. Hence, the design was tested to measure the specific ORR activity of polycrystalline $\mathrm{Pt}$ in $85 \mathrm{wt} \% \mathrm{H}_{3} \mathrm{PO}_{4}$ at $100^{\circ} \mathrm{C}$ and 10 bar oxygen pressure. The results underline the usefulness of the RE system to evaluate the ORR activity in technological relevant electrolytes at elevated temperatures. The test clearly indicates that a temperature of $100^{\circ} \mathrm{C}$ is still too low to overcome activity inhibiting effects related to $\mathrm{H}_{3} \mathrm{PO}_{4}$ electrolyte. Although the RE system is specifically designed for and tested with the RHE in a pressurized cell, it may as well be applied with conventional REs and in other assemblies such as gas diffusion electrode setups; in particular in configurations where in situ determination of the RHE potential is not possible.

\section{Acknowledgment}

The authors acknowledge funding from the European Union Seventh Framework Program (FP7/2007-2013) under grant Agreement No. 309741.

\section{References}

1. G. K. H. Wiberg, M. J. Fleige, and M. Arenz, Rev. Sci. Instrum., 85, 85105 (2014).

2. M. J. Fleige, G. K. H. Wiberg, and M. Arenz, Rev. Sci. Instrum., 86, 64101 (2015).

3. D. D. Macdonald, J. Electrochem. Soc., 126, 908 (1979).

4. G. Hinds and E. Brightman, Electrochem. Commun., 17, 26 (2012).

5. S. Kaserer, C. Rakousky, J. Melke, and C. Roth, J. Appl. Electrochem., 43, 1069 (2013).

6. P. Spitzer and S. Wunderli, in Handbook of Reference Electrodes, G. Inzelt, A. Lewenstam, and F. Scholz, Editors, p. 77, Springer Berlin Heidelberg, Berlin, Heidelberg (2013).

7. B. N. Grgur, N. M. Marković, and P. N. Ross, Can. J. Chem., 75, 1465 (1997).

8. K. J. J. Mayrhofer, S. J. Ashton, J. Kreuzer, and M. Arenz, Int. J. Electrochem. Sci., 4, 1 (2009).

9. M. Yang, S. Lu, J. Lu, S. P. Jiang, and Y. Xiang, Chem. Commun., 46, 1434 (2010).

10. P. J. Peerce and A. J. Bard, J. Electroanal. Chem. Interfacial Electrochem., 112, 97 (1980).

11. M. Chatenet, M. Aurousseau, and R. Durand, Electrochim. Acta, 45, 2823 (2000).

12. H. V. Walters, J. Am. Ceram. Soc., 66, 572 (1983).

13. M. J. Fleige, K. Holst-Olesen, G. K. H. Wiberg, and M. Arenz, Electrochim. Acta, 209, 399 (2016)

14. S. Cherevko, A. A. Topalov, A. R. Zeradjanin, G. P. Keeley, and K. J. J. Mayrhofer, Electrocatalysis, 5, 235 (2014).

15. M. Prokop, T. Bystron, and K. Bouzek, Electrochim. Acta, 160, 214 (2015).

16. W. M. Vogel and J. M. Baris, Electrochim. Acta, 23, 463 (1978).

17. K. Shinozaki, J. W. Zack, R. M. Richards, B. S. Pivovar, and S. S. Kocha, J. Electrochem. Soc., 162, F1144 (2015).

18. K. J. J. Mayrhofer, D. Strmcnik, B. B. Blizanac, V. Stamenkovic, M. Arenz, and N. M. Markovic, Electrochim. Acta, 53, 3181 (2008).

19. H. Gasteiger, S. S. Kocha, B. Sompalli, and F. T. Wagner, Appl. Catal. B Environ., 56, 9 (2005). 